\title{
Evaluation of cost effectiveness and efficacy of commonly used different antacid gel preparations
}

\author{
Vedavathi $\mathbf{H}^{1}$, Tejasvi T $\mathbf{S}^{2}$, Shreenivas P. Revankar ${ }^{1 *}$
}

\author{
${ }^{1}$ Department of Pharmacology, \\ ${ }^{2}$ Department of General \\ Medicine, Shimoga Institute of \\ Medical Sciences, Shimoga, \\ Karnataka, India \\ Received: 8 October 2013 \\ Accepted: 27 October 2013 \\ *Correspondence to: \\ Dr. Shreenivas P. Revankar, \\ Email: sprevankar@yahoo.com \\ (C) 2013 H Vedavathi et al. This \\ is an open-access article \\ distributed under the terms of \\ the Creative Commons \\ Attribution Non-Commercial \\ License, which permits \\ unrestricted non-commercial \\ use, distribution, and \\ reproduction in any medium, \\ provided the original work is \\ properly cited.
}

\begin{abstract}
Background: Gastroesophageal reflux disease (GERD) is a common clinical condition in Indian population. Antacids, which are available as over the counter (OTC) are the commonly prescribed drugs for treatment of GERD. Antacids manufactured and marketed by various multinational and local companies are available in the market. There is need for evaluating the cost effectiveness and efficacy of these antacids as a matter of public concern. Hence the present study was conducted to evaluate the cost effectiveness and efficacy of the commonly prescribed antacid gel preparations.

Methods: Seven different gel formulations of antacids manufactured by different companies were evaluated. Cost effectiveness was done by calculating the cost per $\mathrm{ml}$ of antacid and also by palatability test. Efficacy was evaluated based on acid neutralizing capacity (ANC) of antacid preparations.

Results: The highest cost was $0.305 \mathrm{Rs}$. per $\mathrm{ml}$ and lowest was $0.135 \mathrm{Rs}$ per $\mathrm{ml}$. Palatability score was high at 26.80 and low at 23.85. The antacid with lowest ANC was $20.5 \mathrm{mEq}$ and the highest was $26.5 \mathrm{mEq}$.

Conclusion: Cost effectiveness studies are beneficial in improving the prescribing pattern. It will be a benefit for both doctor as well as patient.
\end{abstract}

Keywords: Antacids, Cost effectiveness, Efficacy, Palatability, Acid neutralizing capacity

\section{INTRODUCTION}

Gastroesophageal reflux disease (GERD) is one of the most prevalent gastrointestinal disorders which is associated with heartburn and regurgitation of gastric contents into the mouth. ${ }^{1}$ Heart burn is induced due to contact of refluxed material on sensitive ulcerated mucosa of esophagus. The important causes of GERD are heavy meals, pyloric obstruction, gastric stasis, hiatal hernia etc. predisposing factors like obesity, ascites and pregnancy also induce GERD. ${ }^{1,2}$ The prevalence of GERD in India is $22-25 \%$ in healthy population, its prevalence in pregnancy is 9.5 to $54 \% .{ }^{3} \mathrm{H}_{2}$ blockers, proton pump inhibitors (PPI), prostaglandin analogues and antacids are some of the categories of drugs used in the treatment of GERD. Antacids are preferred to be the first line of drugs in mild to moderate GERD in pregnancy.

There are a number of antacid preparations available in the pharmaceutical market. Antacid preparations are basically used for treating symptoms like heartburn and dyspepsia. ${ }^{3}$ The ingredients in the antacid preparation are sodium bicarbonate, calcium carbonate, aluminium hydroxide/ phosphate and magnesium citrate/carbonate/ oxide/hydroxide. ${ }^{1}$ Magnesium salts are rapidly acting and aluminium salts are slow acting, a combination of both provide a sustained acid neutralizing action. The laxative effect of magnesium is counteracted by constipating action of aluminium salts, so as to provide a balanced action. ${ }^{4}$

The characteristics of an ideal antacid are: inexpensive, long acting, and palatable. It should be unabsorbable, not cause systemic alkalosis or rebound hyperacidity, and finally should not interfere with absorption and digestive process. $^{2,3}$ Antacids are available in different formulations like tablets, powders, liquids, suspensions and gel. The gel formulations are more preferred as they cover and coat the inflamed mucous membrane. ${ }^{5}$

Antacids are the third most commonly sold over the counter (OTC) drugs after analgesics and antiallergics. ${ }^{6}$ 
As an OTC drug; palatability, cost effective and comparative analytical data is needed to recommend a particular antacid by doctors. There is every possibility of misuse of antacids due to its availability as OTC. Earlier studies have showed that palatability (taste, texture, smell and aftertaste) of medication affects the choice and compliance of patient. So also the cost of antacid also affects the patient's choice. As large number of antacid preparations are available and many more will be entering into the market. From doctor and patient point of view it is very essential to have information regarding cost effectiveness and efficacy of various antacid preparations $^{7}$ available in the local market. Hence the present study was undertaken.

The important feature of antacid preparation is rapid action and effective neutralization of acid. There are various invitro and in vivo tests to evaluate the performance of antacids, ANC (acid neutralization capacity), $\mathrm{pH}$ stat test are few of them. ${ }^{8}$ Measurement of ANC is one of the widely used tests; it was established for the first time by Fordtran and coworkers in 1973. In 1973 John et al conducted a study to evaluate liquid antacids both invitro and in vivo, he suggested that dosage should be determined by milliequivalents of ANC rather than arbitrary volume or number of tablets. ${ }^{6,9}$ According to FDA criteria, antacids must have ANC of at least 5 milli equivalents per dose. In 1981 David et al conducted a study to evaluate the cost effectiveness of various antacid preparations in relation to ANC and concluded that the cost effectiveness of liquids is better than tablets. ${ }^{7}$

\section{METHODS}

The seven different brands of antacid gel preparations commonly available and prescribed in the local area of Shimoga were analyzed for the various properties. For convenience the study was divided under two heads, cost effectiveness and efficacy studies. The cost effectiveness study included the palatability test and cost per $\mathrm{ml}$ of antacid preparation. The efficacy studies were carried out based on the acid neutralizing capacity of the preparation. 8,9

The antacid preparation was evaluated for its smell ,taste, texture and after taste effects .The palatability characteristic was based on a nine point scale(the scoring was as follows; 1- extremely poor,2-poor,3-somewhat satisfactory,4-satisfactory,5-very satisfactory, 6somewhat good, 7-good, 8-very good and 9-excellent), This was similar to the work done by Temple and Nahata. ${ }^{10}$ The study was conducted in the 20 healthy volunteers in a double blinded fashion. Subjects with history of upper respiratory tract infection within one week prior and in study period were excluded so also pregnancy, chronic illness and elderly above 60 years of age were also excluded. The volunteers were refrained from eating or drinking for one hour prior to the test before which instruction was provided regarding definition of taste, texture, smell and after taste. ${ }^{11}$ They were asked to smell, sip and savor, one $\mathrm{ml}$ of the each of the preparations. Between evaluation of each preparation water was provided for gargling to remove any remaining residue and after taste effects. ${ }^{11}$ Evaluation of palatability scores was done using simple statistical analysis.

Acid neutralizing capacity was done in accordance with the Rossetti-rice test. ${ }^{12}$ Dissolve fixed amount of antacid sample in a known amount of $1 \mathrm{~N} \mathrm{HCl}$ solution. The acid reacts with antacid which is a base to form salt and water, fraction of acid is not neutralized, and this is residual. Neutralize the excess amount of $\mathrm{HCl}$ (non reacted $\mathrm{HCl}$ ) by back titrating using a standard solution of $0.5 \mathrm{~N}$ $\mathrm{NaOH}$ ). Note down the volume of $\mathrm{NaOH}$ solution required to back titrate. This gives an estimate of antacid neutralizing capacity (ANC).This can be expressed in form of an equation. ${ }^{9,12}$

$$
\mathrm{N}_{\text {Sample }}=\mathrm{NA}-\mathrm{NB}
$$

NA- number of moles of $\mathrm{HCl}$ used for dissolving the antacid sample.

NB- number of moles of $\mathrm{NaOH}$ required to back titrating the excess $\mathrm{HCl}$.

$\mathrm{N}_{\text {sample }}$ - number of moles neutralized by the sample.

$5 \mathrm{ml}$ of antacid sample was used to which $30 \mathrm{ml}$ of $1 \mathrm{~N}$ $\mathrm{HCl}$ (with an intention that excess amount of $\mathrm{HCl}$ will be left) was added to determine the neutralizing capacity of the sample. ${ }^{6}$ The experiments were undertaken at standard laboratory conditions. Standardization of $\mathrm{HCl}$ and $\mathrm{NaOH}$ was carried out as per USP method. ${ }^{13}$

Procedure: Accurately weighed quantity of uniform mixture, equivalent to the minimum labeled dose was transferred to the flask to which deionised water was added to make up the volume to about $70 \mathrm{ml}$. Standardized solution of $1 \mathrm{~N} \mathrm{HCl}(30 \mathrm{ml})$ was dispensed into the flask and about $70 \mathrm{ml}$ of deionised water was added .The sample was dissolved in this solution and then the mixture was stirred continuously for 15 minutes using a magnetic stirrer so as to get a homogenous suspension. The minimum labeled dosage was pippetted out to a beaker containing $0.1 \mathrm{~N} \mathrm{HCl}$ solution and $\mathrm{pH}$ of the solution was noted. Standardized $0.5 \mathrm{~N} \mathrm{NaOH}$ solution was use for titration of the sample solution until the $\mathrm{pH}$ value of 3.5 was reached. Amount of acid consumed per gram of antacid was expressed in terms of mEq. ${ }^{6,14}$

$$
\text { Practical mEq }=\left(\mathrm{V}_{\mathrm{HCl}} \mathrm{X} \mathrm{N} \mathrm{N}_{\mathrm{HCl}}\right)-\left(\mathrm{V}_{\mathrm{NaOH}} \times \mathrm{N}_{\mathrm{NaOH}}\right)
$$

$\mathrm{V}_{\mathrm{HCl}}$ : volume of $\mathrm{HCl}$ added to the sample

$\mathrm{N}_{\mathrm{HCl}}$ : normality of the $\mathrm{HCl}$ solution

$\mathrm{V}_{\mathrm{NaOH}}$ : volume of $\mathrm{NaOH}$ added to the sample

$\mathrm{N}_{\mathrm{NaOH}}$ : normality of $\mathrm{NaOH}$ 


\section{RESULTS}

The table 1 indicates the scores of the palatability test. The palatability test was conducted on healthy volunteers. The highest palatable score obtained was 26.80 for antacid A3 and the lowest score was 23.85 for antacid A5. It can be noted that there was no much variation in the palatability scores of different antacids. In the present competitive market majority of the manufacturing companies take utmost care to improve the palatability.
It can be found from the above table that the antacid A3 has highest palatability and also high ANC value. in the above study we have found that there was no large differences in the palatability scores and ANC values. There is wide variation in cost between antacid A2 and A5, but no much difference in the values of the ANC. A1 antacid gel was comparatively cheaper but still had good palatability score and high ANC values.

Table 1: Results of palatability test of the seven different antacid preparations.

\begin{tabular}{|lllllll|}
\hline Antacid & $\mathbf{N}$ & Min score & Max-score & Total score & Mean & STD dev \\
\hline A1 & 20 & 18 & 34 & 521 & 26.05 & 4.056 \\
\hline A2 & 20 & 19 & 34 & 486 & 24.30 & 3.609 \\
\hline A3 & 20 & 20 & 34 & 536 & $\mathbf{2 6 . 8 0}$ & 3.430 \\
\hline A4 & 20 & 21 & 30 & 493 & 24.65 & 2.936 \\
\hline A5 & 20 & 16 & 30 & 477 & $\mathbf{2 3 . 8 5}$ & 3.636 \\
\hline A6 & 20 & 20 & 33 & 492 & 24.60 & 3.441 \\
\hline A7 & 20 & 20 & 31 & 504 & 25.20 & 2.580 \\
\hline
\end{tabular}

Table 2: Summary of the various physical and chemical parameters of seven different antacid gels.

\begin{tabular}{|c|c|c|c|c|c|c|c|}
\hline $\begin{array}{l}\text { Antacid } \\
\text { preparation }\end{array}$ & $\mathbf{A 1}$ & $\mathbf{A 2}$ & $\mathbf{A 3}$ & A4 & $\mathbf{A 5}$ & A6 & $\mathbf{A 7}$ \\
\hline $\begin{array}{l}\text { Shelf life } \\
\text { Appearance } \\
\text { Flavor }\end{array}$ & $\begin{array}{l}3 \text { Yrs } \\
\text { White vis* } \\
\text { peppermint }\end{array}$ & $\begin{array}{l}3 \text { Yrs } \\
\text { Pink vis* } \\
\text { vanilla }\end{array}$ & $\begin{array}{l}2 \text { Yrs } \\
\text { Pista vis* } \\
\text { peppermint }\end{array}$ & $\begin{array}{l}\text { 2Yrs } \\
\text { White vis* } \\
\text { Vanilla }\end{array}$ & $\begin{array}{l}2 \text { Yrs } \\
\text { Yellow vis* } \\
\text { mango }\end{array}$ & $\begin{array}{l}\text { 3Yrs } \\
\text { Pink vis* } \\
\text { peppermint }\end{array}$ & $\begin{array}{l}2 \text { Yrs } \\
\text { Orange } \\
\text { vis* } \\
\text { Orange }\end{array}$ \\
\hline $\mathrm{pH}$ & 8.65 & 8.50 & 7.50 & 7.85 & 8.00 & 7.10 & 6.90 \\
\hline $\begin{array}{l}\text { Specific } \\
\text { gravity }\end{array}$ & 1.065 & 1.080 & 1.140 & 1.250 & 1.040 & 1.070 & 1.055 \\
\hline Contents & $\begin{array}{l}\mathrm{AlOH} \\
\mathrm{MgOH} \\
\text { dimethicone }\end{array}$ & $\begin{array}{l}\mathrm{MgOH} \\
\mathrm{PMS} \\
\mathrm{CMC}\end{array}$ & $\begin{array}{l}\mathrm{AlOH} \\
\mathrm{MgOH} \\
\text { dimethicone }\end{array}$ & $\begin{array}{l}\mathrm{AlOH} \\
\mathrm{MgOH} \\
\text { Dimethicone }\end{array}$ & $\begin{array}{l}\mathrm{AlOH} \\
\mathrm{MgOH} \\
\mathrm{PMS}\end{array}$ & $\begin{array}{l}\mathrm{AlOH} \\
\mathrm{CMC} \\
\mathrm{PMS}\end{array}$ & $\begin{array}{l}\mathrm{AlOH} \\
\mathrm{MgOH} \\
\mathrm{CMC}\end{array}$ \\
\hline Cost & $\begin{array}{l}34 \\
\mathrm{Rs} / 200 \mathrm{ml}\end{array}$ & 52.Rs $/ 170 \mathrm{ml}$ & $\begin{array}{l}\text { 50.Rs /170 } \\
\mathrm{ml}\end{array}$ & 30.Rs $/ 170 \mathrm{ml}$ & 27.Rs $/ 200 \mathrm{ml}$ & $29 . \mathrm{Rs} / 170 \mathrm{ml}$ & $\begin{array}{l}32 . \mathrm{Rs} / 170 \\
\mathrm{ml}\end{array}$ \\
\hline Cost $/ \mathrm{ml}$ & 0.170 & 0.305 & 0.294 & 0.176 & 0.135 & 0.171 & 0.188 \\
\hline $\begin{array}{l}\text { Palatability } \\
\text { Score }\end{array}$ & 26.05 & 24.30 & 26.80 & 24.65 & 23.85 & 24.60 & 25.20 \\
\hline ANC (mEq) & 24.0 & 25.8 & 26.5 & 24.5 & 22.5 & 20.5 & 22.5 \\
\hline \multicolumn{2}{|c|}{$\begin{array}{l}\text { AlOH-aluminum hydroxide } \\
\text { PMS-polydimethyl siloxane }\end{array}$} & \multicolumn{3}{|c|}{$\begin{array}{l}\mathrm{MgOH} \text {-magnesium hydroxide } \\
\mathrm{CMC} \text {-carboxy methyl cellulose }\end{array}$} & \multicolumn{3}{|c|}{ Vis*-viscous } \\
\hline
\end{tabular}




\section{DISCUSSSION}

Proton pump inhibitors are nowadays considered to be the drug of choice in the treatment of GERD ${ }^{1}$; they are more effective in preventing recurrences. However aggressive acid suppression may cause hypergastrinemia, there is every possibility of compromise in the absorption of vitamin B12 and calcium. In elderly population and pregnancy vitamin B12 and calcium play a vital role, whose deficiency may lead to developmental defects in fetus and fractures in elderly. ${ }^{1,15}$ So PPI cannot be readily used in these conditions. And, antacids form an alternative medicament for such conditions. ${ }^{1}$

Antacids are very popular as self medication in heartburn and dyspepsia as they are available as over the counter (OCT) .There is every possibility of misuse and lack of awareness regarding the content of antacids. Several studies have been undertaken to determine palatability and in vitro efficacy of OCT antacid brands. ${ }^{6,14}$ In our study we have assessed the cost effectiveness and acid neutralizing capacity of various gel formulations of antacids.

There was a wide variation in the ANC of the preparations. The importance of ANC is highlighted by the earlier studies by Fodtran et al who demonstrated 17 fold variation in potency per $\mathrm{ml}$ of antacids and dare et al demonstrated tenfold difference in ANC between the least and most effective preparations. ${ }^{9}$ In the present study there was not much difference in the ANC of antacid preparations.

The limitations of our study: It failed to study the onset of action, rate of neutralization, duration of action of antacid; which are important factors for determining the efficacy of antacid preparation.

The study is primarily an invitro study. Even though invitro studies simulate in vivo environment antacid activity may vary due to gastric empting, interaction with food and other drugs, variation in acid secretion etc. Batch to batch variation in antacid preparation were not included in our study taking into consideration the uniformity in formula used by manufacturer. But study carried out by Suvarna Bhoir and Bhagwat had included the batch to batch variation. The study can be improved upon by including the other formulations of antacids like tablets, suspensions etc.

\section{CONCLUSION}

The cost effectiveness and efficacy studies are very essential in improving the prescription pattern. They are informative both from patient and doctor point of view. Patient will be benefited by availability of best quality drug at cheaper cost. Doctor will get information regarding the choice of drug for a particular patient.

\section{REFERENCES}

1. Fauci, Braunwald, Kasper, Hauser, Lango, Jameson, Loscalzo. Harrison's principals of internal medicine. $17^{\text {th }}$ Ed; vol (2):1851-52.

2. Vakil N, Vanzanten S V, Kanrilas P, Dent J, Jones R. The Montreal definition and classification of Gastroesaphageal reflux disease. A global evidence based consciousness; Am J Gastroenterology 2006; 101:1900-20.

3. Ramu B, Mohan P, Rajasekharan MS, Jayanthi V. Prevalence and risk factor for Gastroesophageal reflux in pregnancy. Indian J Gastroenterol. 2011;30:144-7.

4. Caranosos GJ, Stewart RB, Cluff LE. Clinically desirable drug interactions. Annual Review of Pharmacology and Toxicology.1985;25:67-95.

5. Schulthen HK. Antacid-gel or tablet, a randomized double-blind, placebo controlled study. Schweiz med wochenschr. 1985;115(29):1069.

6. Suvarna Bhoir, Bhagwath AM. Comparison of seven oxethazine containing antacids available in Indian market. JAPI 2013;61:400-403.

7. David Drake, Daniel Hollander. Neutralizing capacity and cost effectiveness of antacids. Ann Internal Med. 1981;94(2):215-17.

8. Thomson AR, Pinchbeck B, Kirdeikis J, Kirdekis P, Zuk L, Burnet K. Evaluation of antacid tablets and liquids in fasting and fed men and women. Clin Ther 1988;10:158-168.

9. John S, Fordtran MD, Stephan G, Morawaski BA, Charles T, Richardson MD. Invivo and invitro evaluation of liquid antacids. NEJM 1973;288:923-28.

10. Temple ME, Nahata MC. Comparative palatability of 22 liquid antacid. Aliment Pharmacol Ther. 2000;14:421-25.

11. Sadia Nasim, et al. Liquid antacid: a comparative study on palatability and cost effectiveness. Pak J Med Sci 2012;28(1):183-186.

12. Rossett NE, Rice J. Duodenal ulcer producing obstructive jaundice. Gastroenterology 1954;26:490.

13. The United States pharmacopoeia. The national formulary, USP 22, NF 17, united states pharmacopoeial convention, inc., Rockville M.D.,1990, 1528.

14. Gadad AP, Dandagi PM, et al. Non-chewable antacid formulations: effect of different disintegrating agents on their acid neutralization properties. Indian J Pharm Sci. Mar-Apr 2006:26973.

15. Ruff ME, Schotik DA, Bass JW, Vincent JM. Antimicrobial drug suspensions: a blind comparison of taste of fourteen common paediatric drugs. Paediatric Infect Dis J. 1991;10:30-33.

16. Mahadevan U, Kane S. American gastroenterological association institute medical position statement on the use of gastrointestinal medication in pregnancy. Gastroenterology 2006 Jul;131(1):282-87.

doi:10.5455/2319-2003.ijbcp20131222

Cite this article as: H Vedavathi, TS Tejasvi, Revankar SP. Evaluation of cost effectiveness and efficacy of commonly used different antacid gel preparations. Int J Basic Clin Pharmacol 2013;2:788-91. 